\title{
A Laboratory Experiment of Thermals with Generation of Heat
}

\author{
By Hisashi Kon and Choji Magono \\ Department of Geophysics, Hokkaido University, Sapporo \\ (Manuscript received 21 June 1976, in revised form 6 September 1976)
}

\begin{abstract}
A model experiment of the developing stage of a cumulus cloud was performed by the use of $\mathrm{NH}_{3}$ gas and $\mathrm{HCl}$ gas which release heat of reaction by mixing. The white smoke of $\mathrm{NH}_{4} \mathrm{Cl}$ (thermal) grew upwards because of the buoyancy created by heat of reaction.

The thermal had a strong tendency to grow upwards at the vigorous reacting stage and the half-broadening angle was inversely proportional to the height of the top of the thermal. Such properties were also observed in a large natural cumulus cloud. The entrainment coefficient of this thermal was 0.24. This value is in fairly good agreement with that of McCarthy's observation (0.3). The Froude number of thermal in the experiment was estimated as 4.0. This value was larger than that of a thermal with a constant total buoyancy.
\end{abstract}

\section{Introduction}

In order to simulate the cumulus convection, various laboratory experiments have been performed by many workers. The shapes of convection are divided into two types. One is the isolated buoyant mass called thermal or bubble and another is the buoyant column called plume or jet. Scorer and Ronne (1956) and Scorer (1958) carried out a well-known experiment on a thermal in which they released a mass of dyed heavy salt solution into a water and observed its downward growth due to the difference in the density. Ogura (1962) simulated a dry convection by numerical experiments and obtained results which are consistent with Scorer's model. However it was a question whether the results obtained by Scorer's model were directly applicable to the moist convection which accompanies release of latent heat. Turner (1962) introduced a concept of the "starting plume" by combining the thermal with the plume theory. Further in order to examine the effect of release of the latent heat, Turner (1963) performed a laboratory experiment in which supersaturated $\mathrm{CO}_{2}$ gases were educed as minute bubbles from a dilute solution of sodium bicarbonate to simulate the latent heat. Then he pointed out that the half-broadening angle of the plume was a little smaller than that of a thermal with a constant total buoyancy. Yang (1968) conducted an experiment of the upward thermal by a method similar to Turner (1963) in order to simulate a release of latent heat and the increase of diameter at the cloud base.

Recently, Steiner (1973) conducted a threedimensional numerical experiment of cumulus clouds and compared with the results of laboratory experiments. Cotton (1975) discussed the effectiveness of entrainment model.

Meanwhile McCarthy (1974) examined the in-

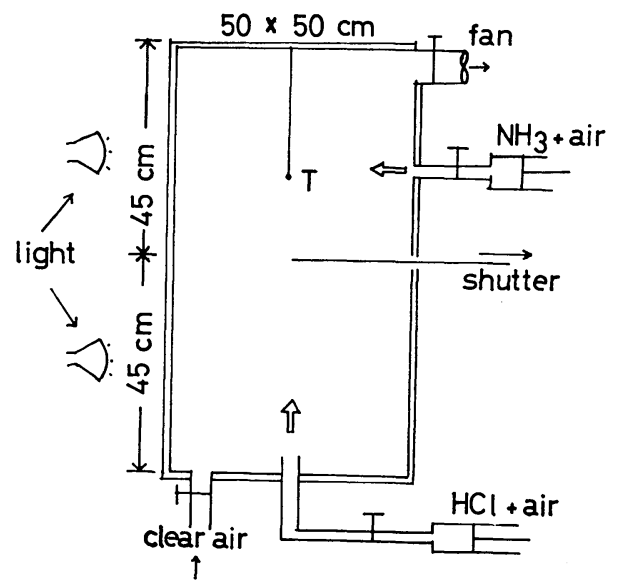

Fig. 1 Experimental apparatus. 
verse relationship of radius: $R$ to the entrainment by an observation of cumulus clouds and estimated the entrainment rate as $0.3 / R$.

The authors attempted an experiment of thermals with gases. A white smoke which was made with $\mathrm{NH}_{4} \mathrm{Cl}$ particles due to the reaction between $\mathrm{HC} 1$ gas and $\mathrm{NH}_{3}$ gas was regarded as a thermal. Three effects were contained in this model experiment; the release of latent heat, condensation level and precipitation. However the main analysis in this paper was focussed on the effect of latent heat.

From the meteorological point of view, it is important to determine whether the results obtained from the model experiment are applicable to cumulus clouds in the atmosphere. So this paper will report also some results obtained from cumulus cloud observations which have been made by stereo-photogrammetric method at Fukue in Kyushu and at Sapporo in summer of 1970.

\section{The equipment and the experimental method}

The experiment was carried out in a box with cross-section of $50 \mathrm{~cm}$ square and $90 \mathrm{~cm}$ deep as shown in Fig. 1. In order to fill only the

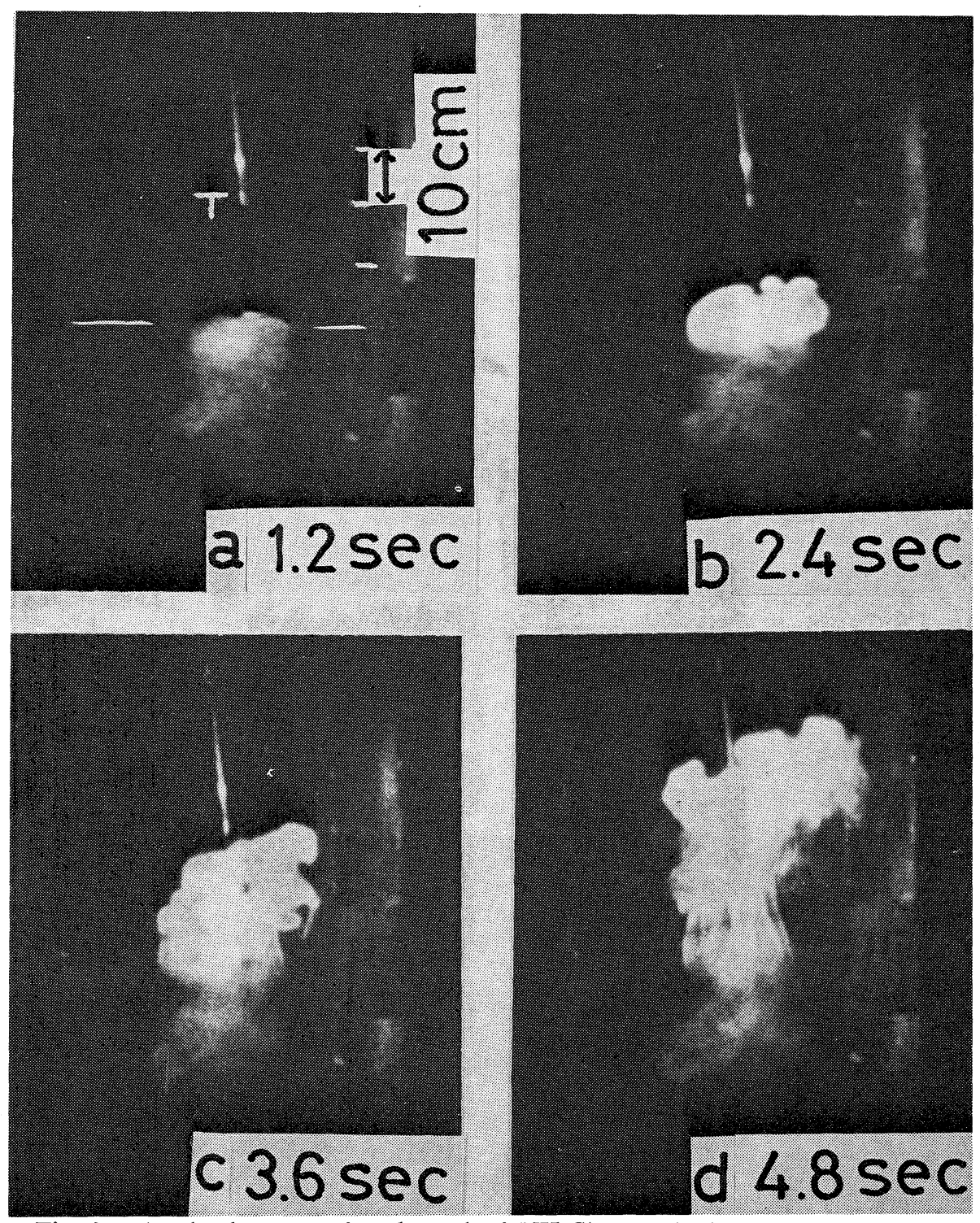

Fig. 2 The development of a thermal of $\mathrm{NH}_{4} \mathrm{Cl}$ gas. A thermocouple is set at the lower end of vertical white line: $T$. 
upper space of the box with $\mathrm{NH}_{3}$ gas, a shutter was set in the middle level. After the turbulence which was risen by the introduction of $\mathrm{NH}_{3}$ gas, calmed down, the shutter was opened. Then $\mathrm{HC} 1$ gas of constant volume was instantaneously shot up as a jet through a nozzle set at the bottom. The gas was forced to rise upwards to contact with $\mathrm{NH}_{3}$ gas in the upper space because $\mathrm{HC} 1$ gas is heavier than air. When the introduced $\mathrm{HC} 1$ gas contacted with $\mathrm{NH}_{3}$ gas, $\mathrm{NH}_{4} \mathrm{Cl}$ smoke was produced at the level of the shutter or a little below and the smoke began to grow upwards, releasing the heat of $42 \mathrm{kcal} / \mathrm{mol}$. It may be regarded that the level at which $\mathrm{NH}_{4} \mathrm{Cl}$ was made by the reaction corresponds to a cloud base or condensation level.

After a run of experiment the gases in the box were drawn out by a fan set in the ceiling and clean air was introduced from the left side of bottom. Then the next experiment was repeated.

The inside of the box was uniformly illuminated. The growth of thermals (smoke region) was recorded with a $16 \mathrm{~mm}$ movie camera from the front of box as illustrated in Fig. 2. The height of the top and the maximum diameter of the thermals were analyzed with the Vanguard Motion Analyzer. The scale of photographs is given in the right hand side of the thermals in the photograph.

The temperature excess of thermals was measured by the rapid temperature rise when the smoke arrived at the thermocouple ( $T$ in Fig. 1). The air temperature was almost uniform in the upper space but was about $1^{\circ} \mathrm{C}$ higher than that of the half below the shutter. Accordingly the air in the box was in general well stratified. However it was unstable for the thermal which was produced owing to the release of heat of reaction. It is desirable for the temperature stratification to be neutral in the box, however it was difficult to remove the temperature difference in the box.

\section{Experimental results}

Photographs in Fig. 2 show a growing process of a thermal. A jet of $\mathrm{HCl}$ gas shot up from the bottom of the box is ascending by reacting with $\mathrm{NH}_{3}$ gas above the shutter level. Numbers at the right bottom of photographs indicate the time after the $\mathrm{HCl}$ gas was introduced into the box. The thermocouple was set in the lower end of a white vertical stem in the center of the box.

The chemical reaction progressed as follows; the outer portion of $\mathrm{HCl}$ gas which contacted with $\mathrm{NH}_{3}$ gas took a form of a membrane of light blue colour of $\mathrm{NH}_{4} \mathrm{Cl}$ and a few knobs came out from a top of the membrane, as seen in Fig. 2 a and b. It may be considered that the chemical reaction already began in the interior of the thermal at that time. At this stage the reaction was vigorous and the outline of the thermal was wholly distinct. After that the thermal increased its upward velocity and finally it struck
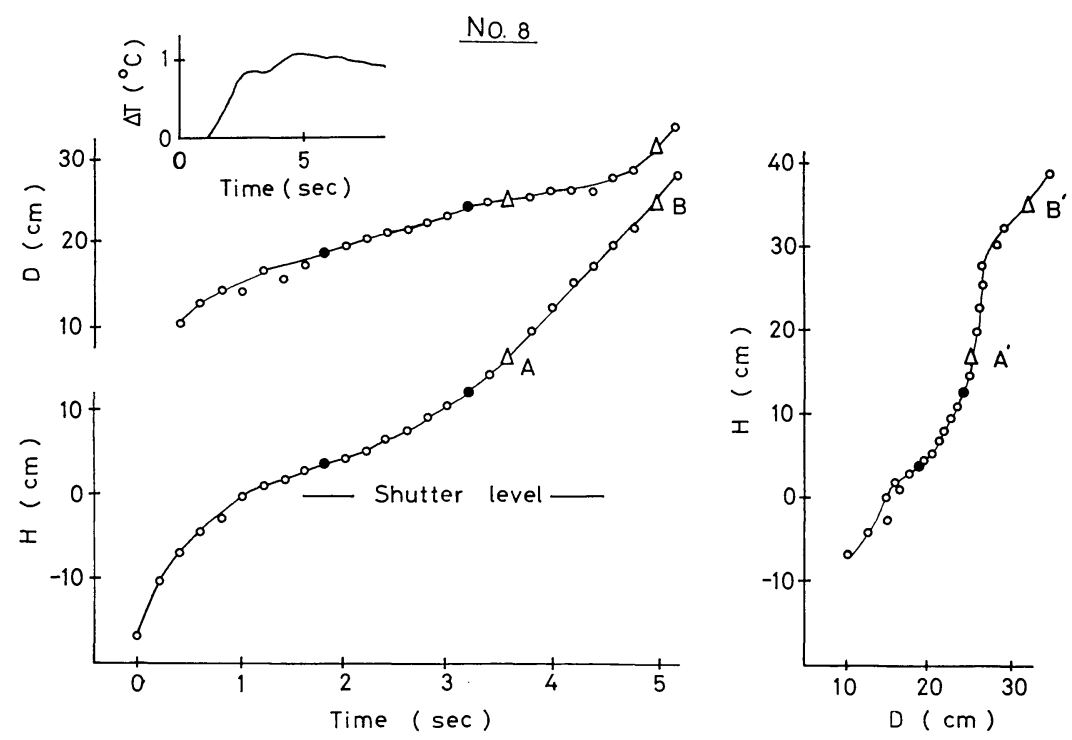

Fig. 3 Time variation of the height of thermal top: $H$ and the maximum diameter of thermal: $D$. The relation of $H$ with $D$ is shown to the right. Temperature variation measured is shown in the left upside. 
the ceiling. The thermal developed in a shape of an inversed cone, however its horizontal dimension at the vicinity of shutter level was constant.

The relations of maximum diameter: $D$ and the height of the top of thermals: $H$ with respect to time were shown in Fig. 3. The height was indicated on the basis of the shutter level. As seen in the figure the upward velocity gradually reduced after shooting below the shutter level. This may be caused by the stable layer below the shutter level and by the load of $\mathrm{HCl}$ gas. But as soon as $\mathrm{HCl}$ gas contacted with $\mathrm{NH}_{3}$ gas and the reaction began above the level, it steeply rose up and increased its upward velocity. After that it rose with an almost constant velocity. A range of curve between two black circles shows the accelerating stage of the thermal and the another range between two triangles shows the stage which is considered to be in a constant upward velocity.

The temperature excess which was measured by the thermocouple is shown in the left top of Fig. 3. Since the thermocouple is fixed at a point, the time change in the temperature excess is caused by the passage of the thermal. It is seen in the figure that the excess temperature increased by one degree at the top of the thermal and was almost constant in the trunk of the thermal.

\section{3-1. The variation of the maximum diameter}

As shown in Fig. 3, the maximum diameter: $D$ increased linearly with time in the accelerating stage. Therefore, $D$ may be expressed by a relation

$$
D=2 u_{0} t+\text { const. }
$$

where $u_{o}$ is the horizontal velocity of thermal edge and $t$ is the time.

The relation between the height of thermal top and the maximum diameter is shown in the righthand side in Fig. 3. It may be seen that the half-broadening angle $(1 / 2 d D / d H=d R / d H)$ increased at the vicinity of the site of the shutter. This may be because the ascending motion of thermal was restricted by the stable layer near the shutter level and extended horizontally. After passing the shutter level, however, the angle extremely reduced according to the rapid growth of thermal due to the evolution of reaction. Such reduction in the angle was not clearly seen in experiments conducted by other workers. Above $30 \mathrm{~cm}$ height, maximum diameter again increased. This may be caused by the effect of the disturbance due to the ceiling.

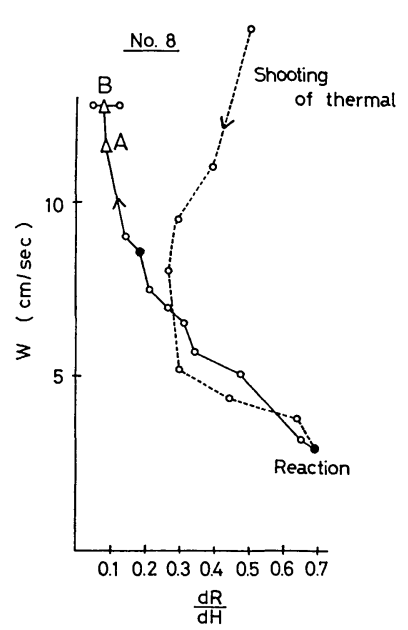

Fig. 4 Variation of the half-broadening angle against the vertical velocity. The arrows show the time lapse. A dotted curve shows the upward velocity in pre-reaction and a solid curve shows the velocity during reaction.

Fig. 4 shows the relation between broadening angle and upward velocity of thermals. The black circles and the triangles in the figure correspond to those in Fig. 3, and arrows show the direction of time lapse. As shown in a dotted line, the upward velocity was decreasing until the time of reaction, but after the reaction it was accelerated as shown by a solid line. On the other hand, as the upward velocity increased, the half-broadening angle was reduced to a value of about 0.1 as seen in the figure. This change in the angle shows that the ascending parcel takes a form of "thermal" at the earlier decelerated stage where $\mathrm{HCl}$ gas is diluted and it approaches to the "plume" in the late accelerating stage.

\section{3-2. The relation between the height of the top and the maximum diameter}

If we describe the height of the thermal top in a logarithmic scale as shown in Fig. 5, it may be seen that in the accelerating stage the relation between the height of thermal and the time is described by

$$
H \propto \exp (\sigma t)
$$

where $\sigma$ is the growth rate of the thermal top. This formula is in agreement with the result obtained by Ogura (1963) in the numerical experiment of a moist convection in the conditionally unstable layer.

Eliminating the time: $t$ from formula (1) and 

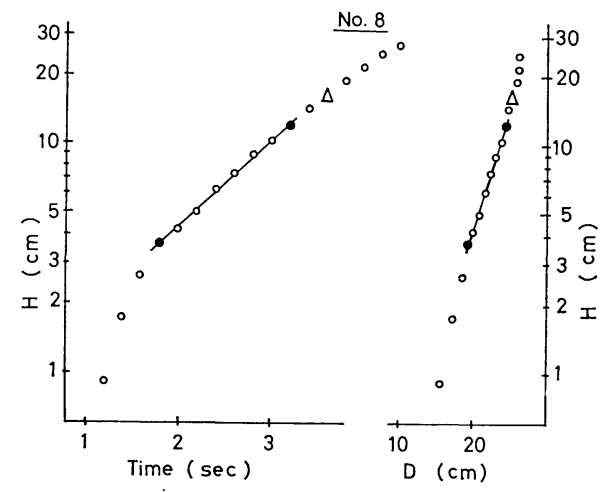

Fig. 5 Time variation of the height of the top of a thermal and the height vs the maximum diameter.

(2), one obtained the following relation between the height of the top and the maximum diameter:

$$
H \propto \exp \left(\sigma D / 2 u_{0}\right)
$$

This formula corresponds to the $H-D$ relation in Fig. 5. Differentiating formula (3) with $D$, one obtains

$$
\frac{d R}{d H}=\frac{u_{0}}{\sigma H}
$$

Here the half-broadening angle is described as a function of the thermal top. It may be seen that the shape of the thermal changes from a conical to columnar form as the height increases. In this experiment the growth rate: $\sigma$ was $1.4 \mathrm{sec}^{-1}$ and the horizontal broadening velocity: $u_{o}$ was $1.9 \mathrm{~cm}$ $\mathrm{sec}^{-1}$.

\section{3-3. The Froude number of the thermal}

The Froude number is given by

$$
F=C^{2}=\frac{W^{2}}{g B R}
$$

where $W, R$ and $B$ are the upward velocity of a thermal, the maximum radius of the thermal and the buoyancy represented by $\Delta T / T$, and $g$ is the gravitational acceleration. $\Delta T$ is the temperature excess of the thermal over the environmental air. $C$ is a well used number for the vertical motion due to the buoyancy. The value of the upward velocity was determined by the inclination of a linear part of $H$-Time curve between triangles $A$ and $B$ in Fig. 3. Because the radii of the thermal at $\mathrm{A}$ and $\mathrm{B}$ were different from each other, the mean radius was adopted as the characteristic dimension which was calculated from
Table 1. $C$ values: square root of Froude number.

\begin{tabular}{|ccccc|}
\hline No. & $\mathrm{W}(\mathrm{cm} / \mathrm{sec})$ & $\mathrm{R}(\mathrm{cm})$ & $\Delta \mathrm{T}\left({ }^{\circ} \mathrm{C}\right)$ & $\mathrm{C}$ \\
\hline 1 & 12.6 & 9.0 & 1.1 & 2.2 \\
2 & 10.4 & 9.5 & 1.5 & 1.5 \\
3 & 9.8 & 15.0 & 0.5 & 1.9 \\
4 & 14.0 & 12.5 & 0.85 & 2.3 \\
5 & 11.8 & 13.8 & 0.85 & 1.9 \\
6 & 13.0 & 15.2 & 0.95 & 1.8 \\
7 & 16.0 & 10.3 & 2.1 & 1.8 \\
8 & 13.4 & 14.2 & 1.3 & 1.7 \\
9 & 16.8 & 9.7 & 1.5 & 2.4 \\
10 & 20.8 & 15.3 & 1.4 & 2.4 \\
\hline & & & Mean & 2.0 \\
\hline
\end{tabular}

diameters $\mathrm{A}^{\prime}$ and $\mathrm{B}^{\prime}$ in $H-D$ curve in the figure. As for the temperature excess, the maximum value in the $T$-Time curve in Fig. 3 was employed. Using these values the $C$ values were calculated for ten runs, as shown in table 1. These values of $C$ were roughly the same, the average being 2.0 .

3-4. The half-broadening angle in the constant upward velocity stage

Let us derive the half-broadening angle, utilizing one-dimensional equation of motion. The equation of momentum conservation of the thermal can be expressed as

$$
\frac{d W}{d t}=g B-\frac{W}{M} \frac{d M}{d t}
$$

where $M$ is the mass of a thermal and equal to $\rho V$. If the shape of the thermal is invariable, the volume: $V$ is given by the following formula

$$
V=m R^{3}
$$

where $m$ is a constant depending on the shape of the thermal. Then we have

$$
\frac{d R}{d H}=\frac{1}{3 C^{2}}
$$

in the constant velocity stage. From the obtained value of $C: 2.0$, we have

$$
\frac{d R}{d H}=0.08
$$

This value is in good agreement with that obtained by the experiment No. 8 as seen in the left top of Fig. 4. This value corresponds to the value of the entrainment coefficient: 0.24 if the shape of the thermal was assumed to be a sphere. The authors adopted the definitions that the entrainment rate is $k d R / R d H, k$ is a configuration 
constant, $d R / d H$ is the half-broadening angle and $k \cdot d R / d H$ is the entrainment coefficient.

\section{Observational results of natural cumulus clouds}

Observations of cumulus clouds were conducted in order to examine the half-broadening angle and the value of $C$ in natural cumulus clouds. Sequence pictures of clouds in Fig. 6 were taken in the cloud observation at Fukue, Kyushu (Kon et al. 1975). The time change of the height and the diameter of the cumulus located at the righthand side of the figure was analyzed as shown in Fig. 7. It is seen in this figure that the maximum diameter of the cloud increased linearly with time and its height increased exponentially with time at least up to 1517. Comparing the figure with Fig. 5, it may be seen that these
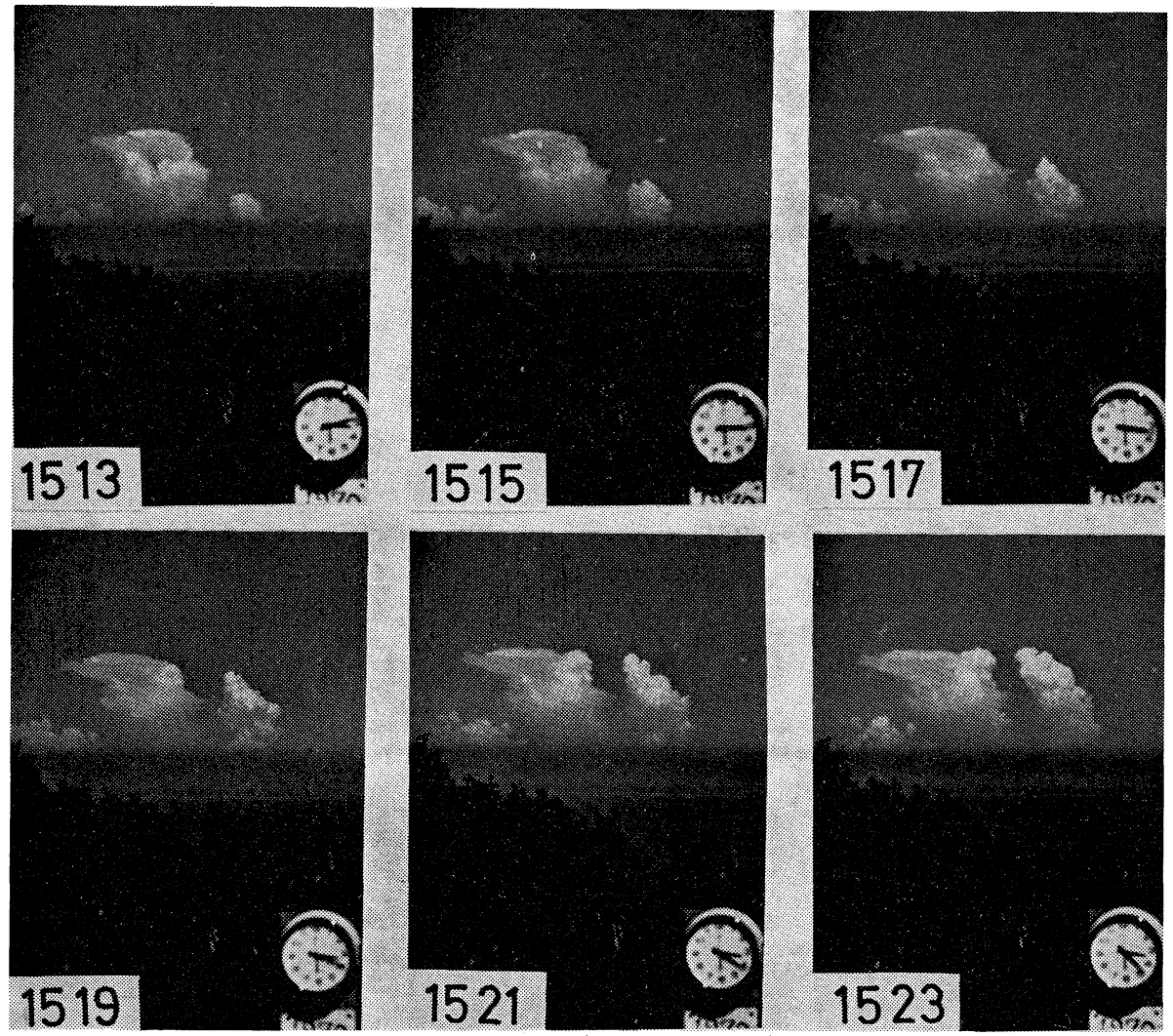

Fig. 6 The growth of cumulus clouds observed at Fukue. The cloud to the right was analyzed. July 24, 1970.

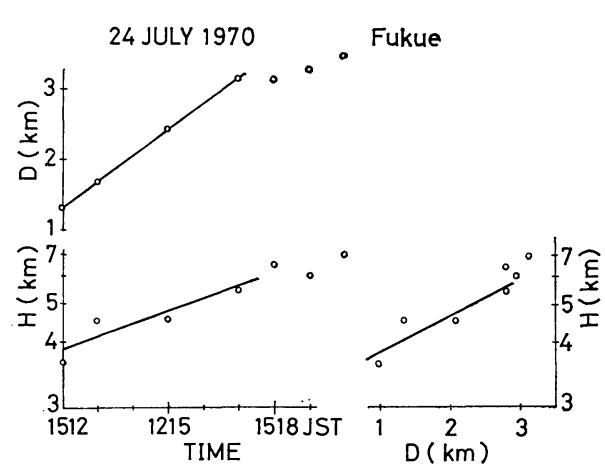

Fig. 7 Similar to Fig. 5 but for a cloud observed in Fukue. results are qualitatively in agreement with those of the laboratory experiment. However the Froude number of the cloud was not obtained, because the temperature excess was not measured. The growth rate and the broadening velocity of the cumulus cloud estimated in the linear portion in Fig. 7 were $1.3 \times 10^{-3} \mathrm{sec}^{-1}$ and $3.1 \mathrm{~m} / \mathrm{sec}$, respectively.

Cumulus clouds were also measured in their early stage in Sapporo (Chiyu et al. 1973). Froude number were calculated for small cumulus clouds. In this case the parcel method may be applicable to estimate the temperature excess. The analysis was made for two cumulus clouds indicated by 

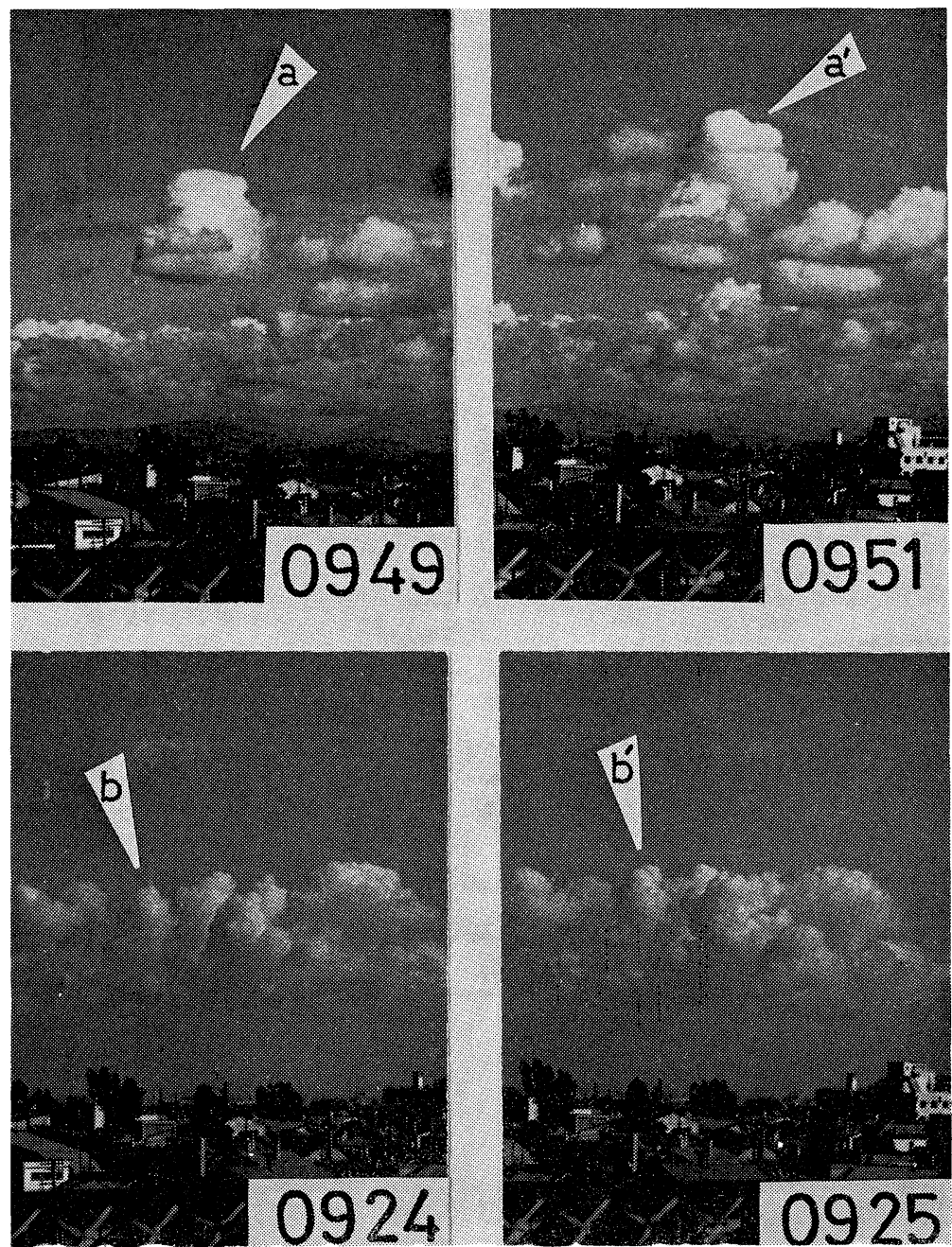

Fig. 8 The growth of cumulus clouds observed in Sapporo. Arrows show the cloud analyzed. Sept. 13, 1970.

arrows in Fig. 8. The time of photographing is shown below each picture. The maximum upward velocity of cloud top and the maximum radius of newly protruded portion of clouds were adopted as the characteristic values to calculate the Froude number. Although the temperature excess and the grade of entrainment were not directly measured, the entrainment may be neglected, because a new thermal was born from its

Table 2. $C$ values of clouds observed in Sapporo.

13 SEPT. 1970

\begin{tabular}{|c|c|c|c|c|c|}
\hline NO. & $\mathrm{H}(\mathrm{km})$ & $W(\mathrm{~m} / \mathrm{sec})$ & $R(\mathrm{~km})$ & $\Delta \mathrm{T}\left({ }^{\circ} \mathrm{C}\right)$ & $C$ \\
\hline 1 & 1.4 & 4.6 & 0.20 & 0.9 & 1.8 \\
\hline 2 & 1.6 & 2.7 & 0.22 & 0.9 & 1.0 \\
\hline & & & & \multicolumn{2}{|c|}{ Mean 1.4} \\
\hline
\end{tabular}

mother cloud volume. Therefore, it may be allowed to use the parcel method. Then the $C$ values of the two cumulus clouds were calculated as 1.8 and 1.0 as listed in table 2 .

\section{Discussion}

It is generally said that the entrainment coefficient in the laboratory experiment is 0.6 for a thermal which is diluted without mass supply from below and 0.2 for a plume which is compensated by updraft from below (Cotton, 1975). For small cumulus clouds McCarthy (1974) got a value of 0.3 . In the present experiment the value was 0.24 for a constant velocity stage. At this stage it is considered that the thermal was diluted by entrainment, on the other hand it acquired buoyancy due to the release of the heat 
of chemical reaction. It may be concluded from the results described above that the entrainment coefficient is fairly variable, depending on the increase or decrease of buoyancy.

The value of $C$ (square root of Froude number) obtained by the present experiment are compared with those by earlier workers as shown in table 3. The Scorer's $C$ value is considerably smaller than the present thermal with heat generation, because when heat is released the halfbroadening angle becomes small and $C^{2}$ is inversely proportional to the angle. It is interesting that the values of $C$ of natural cumulus clouds were intermediate between those of two kinds of thermal.

Table 3. Comparison of $C$ values with those obtained by other workers.

\begin{tabular}{lll}
\hline Experiment & $C$ & Investigators \\
\hline Thermal (liquid) & 1.2 & Scorer \\
Cumulus & 1.5 & Saunders \\
Thermal (gas) & 2.0 \\
Cumulus & 1.4 & The authors \\
Sphere (solid) & $2.4^{*}$ & \\
\hline
\end{tabular}

* The value was calculated with the drag coefficient of a sphere under steady state.

Since the cumulus cloud observed in Fukue developed into the cumulonimbus later, it is supposed that the cloud had been accompanied with much greater release of latent heat than the cumulus cloud observed in Sapporo. Accordingly it may be predicted that the property of cloud at Fukue will be much similar to that of our thermal model.

\section{Conclusion}

The development of the thermal in our laboratory experiment can be classified in the three stages: decelerated stage, accelerated stage and finally constant velocity stage. In the accelerated stage the maximum diameter of thermals increased linearly with time and the height of the top increased exponentially with time. Such increase of diameter and cloud top was also observed in cumulus cloud in Fukue. Accordingly the half-broadening angle was inversely proportional to the height of the top of thermal and cloud.

In the constant velocity stage the angle was nearly constant as 0.08 .

Froude number of the thermal in the model experiment was larger than that in the experiment by Scorer. This was caused by the release of heat. The Froude number of natural cumulus cloud was intermediate between those of thermal with release of heat and thermal without release of heat as of Scorer.

\section{Acknowledgements}

The authors wish to express their thanks to Dr. T. Endoh who suggested the idea of this experiment about the release of heat.

The computation in the analysis of observation were made on FACOM 230-60 at the Hokkaido University Computing Center.

\section{References}

Chiyu, T., H. Kon and C. Magono, 1973: The movement of cumulus humilis clouds. J. Meteor. Soc. Japan, 51, 43-53.

Cotton, W. R., 1975: On parameterization of turbulent transport in cumulus clouds. J. Atmos. Sci., 32, 548-564.

Kon, H., T. Harimaya, T. Chiyu and C. Magono, 1975: A cloud row observed in the lee of a small island. J. Meteor. Soc. Japan, 53, 241-246.

McCarthy, J., 1974: Field verification of the relationship between entrainment rate and cumulus cloud diameter. J. Atmos. Sci., 31, 1028-1039.

Ogura, Y., 1962: Convection of isolated masses of a buoyant fluid: A numerical calculation. $J$. Atmos. Sci., 19, 492-502.

- 1963: The evolution of a moist convection element in a shallow conditionally unstable atmosphere: A numerical calculation. J. Atmos. Sci., 20, 407-424.

Saunders, P. M., 1961: An observational study of cumulus. J. Met., 18, 451-467.

Scorer, R. S. and C. Ronne, 1956: Experiments with convection bubbles. Weather, 11, 151-154.

- 1957: Experiments on convection of isolated masses of buoyant fluid. J. Fluid Mech., 2, 583-594.

Steiner, J. T., 1973: A three-dimensional model of cumulus cloud development. J. Atmos. Sci., 30, $414-435$.

Turner, J. S., 1962: The 'starting plume' in neutral surrounding. J. Fluid Mech., 13, 356-368.

1963: Model experiments relating to thermals with increasing buoyancy. Quart. J.R. Meteor. Soc., 89, 62-74.

Yang, I. K., 1968: Some model experiment of condensation. Proceeding of the International Conference on Cloud Physics, Toronto, August, 2630, 529-533. 


\section{発熱する Thermal の室内実験}

\section{今 久・孫野長治}

北海道大学理学部地球物理学教室

混合すると反応によって熱を放出するアンモニアガスと塩化水素ガスを使用して Thermal のモデル実験を行っ た。塩化アンモニウムの白煙（Thermal）は反応熱の放出によって成長しながら上昇する。

Thermal は反応の時期に強く成長する傾向を持ち広がりの角は Thermal Top の高さに逆比例した。そのような 傾向は天然の積雲においても観測された。エントレーメントの係数は 0.24 であった。この值は McCarthy の観測 による値 0.3 とょく一致している。Thermal のフルード数は 4.0 と見積られた。この值は全浮力一定の Thermal より大きかった。 